\title{
Formas asociativas sin ánimo de lucro más convenientes para desarrollar agronegocios en el Departamento de Antioquia
}

Convenient non-profit associative forms to develop agrobusiness in Antioquia

\section{As formas associativas sem fins lucrativos mais convenientes para desenvolver o agronegócio no Departamento de Antioquia}

\section{Gabriel Antonio Acevedo González ${ }^{1}$ Yomar Javier Sánchez Caicedo ${ }^{2}$}

Recibido: 9 de agosto de 2020

Aprobado: 1 de abril de 2021

Publicado: 10 de mayo de 2021

Cómo citar este artículo:

Acevedo, A. y Sánchez, Y. (2021). Formas asociativas sin ánimo de lucro más convenientes para desarrollar agronegocios en el Departamento de Antioquia.

Cooperativismo \& Desarrollo, 29(120), 1-22.

doi: https://doi.org/10.16925/2382-4220.2021.02.05

Artículo de investigación. https://doi.org/10.16925/2382-4220.2021.02.05

1 Zootecnista, Especialista en Mercadeo Agropecuario y Magíster en Administración de Empresas (MBA). Profesor Asociado del Politécnico Colombiano Jaime Isaza Cadavid (Medellín, Colombia).

Correo electrónico: gaacevedo@elpoli.edu.co

ORCID: https://orcid.org/0000-0002-0014-6590

2 Economista y Magíster en Administración de Empresas (MBA). Profesor del Politécnico Colombiano Jaime Isaza Cadavid (Medellín, Colombia).

Correo electrónico: yjcaicedo@elpoli.edu.co

ORCID: https://orcid.org/0000-0002-4674-6399 
2 Formas asociativas sin ánimo de lucro más convenientes para desarrollar agronegocios en el Departamento de Antioquia

\title{
Resumen
}

Introducción: un limitante para la sostenibilidad de los pequeños y medianos productores agrarios es el sistema de comercialización, caracterizado por actores con alto poder de negociación (compradores) y otros con poca capacidad de negociación (productores). Para conseguir la posición competitiva los campesinos deben asociarse, conformando agronegocios asociativos sin ánimo de lucro (ASAL), con alto poder de negociación y la solidez suficiente como para ser sostenibles. Los productores tienen claro que al asociarse obtienen mejores resultados; sin embargo, hay gran escepticismo para crear nuevas empresas asociativas, y es frecuente la pregunta: ¿Qué forma asociativa sin ánimo de lucro (SAL) es la más indicada para una empresa grande? Para responder esta pregunta se requiere más información que soporte las propuestas, lo que motiva esta investigación.

Metodología: se construyó un marco muestral de ASAL existentes en los 125 municipios del departamento de Antioquia, también se calculó una muestra de 50 ASAL ubicados en 29 pueblos, finalmente se aplicó entrevista de profundidad a 7 líderes de alta relevancia y se realizaron diversos procesos de observación participativa.

Resultados: se obtuvo argumentos en pro y en contra de varias formas asociativas para desarrollar agronegocios ante diferentes situaciones.

Conclusiones: el $68 \%$ de los ESAL, que quieren cambiar su forma empresarial, se inclinan por la cooperativa, ya que la consideran más apropiada para desarrollar ASAL con alta capacidad competitiva. Para grupos pequeños, homogéneos y con alta capacidad de inversión podría ser viable la Sociedad Agraria de Transformación (SAT).

Palabras clave: agronegocio, competitividad, forma asociativa, poder de negociación, sostenibilidad

\section{Descriptores:}

P32 Colectivos $\cdot$ Comunas • Agricultura

J54 Cooperativas de productores

P13 Cooperativas $\cdot$ Agronegocios

\begin{abstract}
Introduction. A limitation for the sustainability of small and medium-sized agricultural producers is the marketing system, characterized by actors with high negotiation power (buyers) and others with low power (producers). To achieve a competitive position, farmers must associate, forming non-profit associative agribusinesses with high negotiation power and sufficient solidity to be sustainable. Producers are clear on the fact that by associating they obtain better results; however, there is great skepticism about creating new associative companies, and the question on which non-profit association is the most convenient for a large company is frequently asked. To answer this question, more information is required to support the proposal that motivates this research.
\end{abstract}

Methodology. A sample framework of non-profit associations from 125 Antioquia municipalities was constructed, it was also calculated a sample of 50 non-profit associations from 29 town. Finally, a profound interview was conducted with 7 high profile leaders, and various processes of participant observation were realized.

Results. Arguments were obtained for and against various associative forms to develop agribusiness in different situations.

Conclusions. $68 \%$ of non-profit enterprises, that want to change their business form, are inclined towards cooperative, since they are considered more appropriate to develop a highly competitive capacity non-profit association. For small, homogenous groups with high investment capacity, the Agrarian Transformation Society (ATS) could be viable.

Keywords: agrobusiness, competitivity, associative form, negotiation power, sustainability. 


\section{Resumo}

Introdução: uma limitação para a sustentabilidade dos pequenos e médios produtores agrícolas é o sistema de comercialização, caracterizado por atores com alto poder de barganha (compradores) e outros com pouco poder de barganha (produtores). Para alcançar uma posição competitiva, os camponeses devem se associar, formando associações agroindustriais sem fins lucrativos (ASAL), com alto poder de barganha e solidez suficiente para serem sustentáveis. Os produtores têm claro que associando obtêm melhores resultados; no entanto, há um grande ceticismo em relação à criação de novas empresas associativas, e a pergunta é frequente: Qual a forma associativa sem fins lucrativos (SAL) é a mais adequada para uma grande empresa? Para responder a essa pergunta, são necessárias mais informações para fundamentar as propostas, o que motiva esta pesquisa.

Metodologia: foi construído um quadro de amostragem de ASALs existentes nos 125 municípios do departamento de Antioquia, também foi calculada uma amostra de 50 ASALs localizadas em 29 cidades, finalmente foi aplicada uma entrevista em profundidade a 7 líderes altamente relevantes e vários processos de avaliação foi realizada observação participante.

Resultados: foram obtidos argumentos a favor e contra diversas formas associativas para desenvolver o agronegócio em diferentes situações.

Conclusões: $68 \%$ das ESALs, que pretendem mudar a sua forma de negócio, estão inclinadas para o cooperativismo, pois consideram mais adequado desenvolver ASALs com elevada capacidade competitiva. Para grupos pequenos e homogêneos com alta capacidade de investimento, a Sociedade de Transformação Agrária (SAT) poderia ser viável.

Palavras-chave: agronegócio, competitividade, forma associativa, poder de barganha, sustentabilidade

\section{Introducción}

Gran parte de los agricultores se ubican en zonas montañosas de poco potencial y cuentan con tierras de regular calidad. Adecuar, para que estas tierras tengan una buena productividad, se deben hacer altas inversiones que muchos no pueden efectuar porque tampoco cuentan con la motivación y el apoyo del Estado u otros actores en favor del desarrollo; a lo que se suman los altos costos y los bajos precios de venta, como resultado de su baja capacidad de negociación. Caicedo (2013), a partir del análisis de productores del corregimiento de San Cristóbal (Medellín), concluye que la intermediación mayorista le permite al campesino alcanzar tan solo márgenes de supervivencia, lo que conlleva una pobre calidad de vida y desestimula la continuidad de la producción. Muchos campesinos tienen claro que la solución a esta situación implica la creación de empresas asociativas SAL, razón por la que han ensayado todas las formas asociativas sin una asesoría experta, dado que el Gobierno carece de una política a este respecto y solo promueve pequeñas asociaciones como canal para llevar apoyos o proyectos, generando una larga historia de fracasos. 
En consecuencia, hay un mal ambiente para procesos asociativos porque abunda el egoísmo, la prevención y el miedo; también porque se han hecho demasiados ensayos y son pocos los proyectos exitosos que logran permanecer en el tiempo. Los pueblos agrarios requieren empresas asociativas SAL con el alcance suficiente para beneficiar a todos los productores y con un tamaño que les permita ser sostenibles y competitivas. Similar realidad se encontró en Perú, Ferrando (2015) y Cáceres, Pardo y Torres (2013) consideran que, para lograr sensibilizar y motivar a los productores rurales a crear organizaciones solidarias sostenibles, es necesario juntar un equipo interdisciplinario e interinstitucional capaz de fortalecer las cadenas productivas con inclusión de los pequeños y medianos productores, con lo cual se podría recuperar la confianza perdida.

Los productores agrarios, en su mayoría micro, pequeños y medianos (Mipymes), están sumidos en un sistema económico que no les permite progresar, salvo excepciones, por lo que se percibe como inequitativo e injusto. Para lograr una economía más justa y equitativa es necesario que las empresas mercantiles asuman una filosofía más responsable con la sociedad; que el Estado avance en la mejora de los bienes públicos como insumo para la competitividad rural; que haya más apoyo del Estado a la labor de los campesinos, junto con un manejo financiero más ético, de modo que el lucro de unos no implique la ruina de los otros; que se desarrolle un comercio justo en el que se pague un precio remunerativo al productor, un margen moderado al intermediario y precio asequible al consumidor.

Lograr esto parece imposible, puesto que cada actor está inmerso en su juego de intereses y poderes, solo piensa en los resultados que busca y no tiene tiempo para mirar atrás y valorar el impacto negativo de sus acciones. ¿Qué deben hacer entonces los productores que quieren mantener su actividad con la calidad de vida deseada? Todo indica que se tienen que apropiar de su destino y no esperar actos de generosidad de nadie, de modo que el camino es asociarse y crear sus propias empresas. Cárdenas y Manzanares (2017), en sus estudios acerca de la dinamización de la agricultura en el Casanare, ratifican que la economía solidaria es la clave para el fortalecimiento de las actividades que se desarrollan en las cadenas de valor, incrementar los beneficios, atraer distintos apoyos y obtener ventajas tributarias que hagan más sostenibles los procesos.

Mediante la observación y el diálogo con habitantes de pueblos predominantemente agrarios de Antioquia, se percibe una economía relativamente estancada que no logra generar oportunidades para desarrollar un proyecto de vida digno para los jóvenes. Esto deriva en altos niveles de migración del campo al pueblo y de este a las 
capitales. Como consecuencia de este panorama, se ha reducido a niveles dramáticos la población que habita en las fincas, a la vez que se aumenta la edad promedio.

El Banco Mundial prevé que para 2050 en el mundo solo habrá un 32 \% de habitantes en el campo. Según el Programa de las Naciones Unidas para el Desarrollo -PNUD (2016) y el Censo Nacional Agropecuario del 2015, este panorama ya es una realidad para Colombia, pues solo el 27,6 \% de propietarios de fincas viven en ellas. Esto evidencia la urgencia por dinamizar la economía de los pueblos, y ya que son predominantemente agrarios y que lo que genera y mueve el dinero son las empresas, se identifica la necesidad de crear ASAL con alto poder de negociación. Lo que no está muy claro es la forma empresarial que se debe crear, lo cual motiva la realización de esta investigación.

Algunos elementos esenciales para los emprendimientos asociativos futuros de los campesinos incluyen: iniciar con la forma adecuada de ASAL, definir un modelo exitoso de negocio, una adecuada estrategia comercial, el tamaño de operación que permita ser competitivo y sostenible, entre otros; especialmente en este momento, cuando se inicia la implementación de la política pública para la economía social y solidaria en el departamento de Antioquia.

\section{Marco teórico}

En la economía de un pueblo predominantemente rural y la necesidad de emprendimientos solidarios,

La denominación de pueblo rural puede hacerse desde el tamaño de la población urbana, pero también desde el tipo de actividad y de las relaciones económicas y culturales de lo urbano con lo rural. Para Posada (2010), en el 69 \% de los pueblos colombianos es mayor la población rural que la urbana, con topes de hasta el $95 \%$ rural, siendo fuerte la tendencia a la migración. La mayoría de los pueblos predominantemente rurales basan su economía en actividades agrarias, luego en general pueden definirse como pueblos rurales o agrarios. (Bendini y Steimbreger, 2011, p. 6).

La migración de la familia campesina al casco urbano, manteniendo la unidad productiva rural, se da por la búsqueda de seguridad, acceso a bienes públicos y a una mejor calidad de vida, lo que es difícil de lograr en regiones con débil desarrollo rural. Por lo expuesto, muchos habitantes urbanos se autoabastecen de productos de su finca y no los buscan en el pueblo, lo que hace que una oferta moderada 
6 Formas asociativas sin ánimo de lucro más convenientes para desarrollar agronegocios en el Departamento de Antioquia

resulte excesiva por falta de compradores. Según el PNUD, "el 77 \% de los pueblos de Colombia se consideran rurales, por tener población urbana inferior a 20.000 habitantes, y principalmente por su dependencia de actividades agrarias, lo que permite estimar que el 32 \% de los habitantes de Colombia son rurales" (2011, p. 15). Un claro ejemplo de esta problemática es la zona suroriental del oriente antioqueño, en donde el 68 \% de la población es rural dispersa y la dinámica urbana se da en estricta relación con lo rural (CORNARE, 2015).

Un pueblo rural cuenta con una alta dinámica agraria y una incipiente actividad industrial o artesanal, se complementan la actividad económica con algunos servicios como el transporte, la mecánica, los repuestos y servicios públicos, entre otros. En estos pueblos la actividad que más genera dinero es la agraria, en este sentido, puede decirse que el motor de la economía es la actividad agropecuaria y los servicios conexos; en otras palabras, si al agro le va bien, al resto del pueblo también. Con el fin de obtener una mejor comprensión de la dinámica de estas zonas, mediante la colaboración de líderes de varios pueblos, se identificaron los oficios más frecuentes, tal y como se expone a continuación: agropecuaria y servicios conexos $79 \%$, servicios varios $7 \%$, industria $2 \%$ y construcción $1 \%$.

Según Acevedo (2019), el comportamiento cíclico de la economía agraria es equivalente a la economía del pueblo, por lo tanto, la administración municipal o de las comunidades campesinas debe generar una dinámica agraria y agroindustrial que permita un desarrollo más equilibrado y sostenible, tratando de estabilizar los ciclos con intervención en todos los eslabones de la cadena de valor agraria, con énfasis en el área más débil que ha sido el mercadeo de los productos. Para Acevedo (2019), además de un componente educativo, es vital dinamizar la economía del pueblo y ese es el papel de las empresas. En escenarios predominantemente agrarios, esta labor la deben realizar los ASAL, cuya responsabilidad es activar la economía local y generar oportunidades para las personas.

Generar una dinámica económica mayor, parte de comprender la situación en que viven los productores rurales que, según el PNUD (2011), son pequeños en un $88 \%$. Acevedo y Palacio (2017) plantean que los pequeños productores disponen de una oferta dispersa, heterogénea y difícilmente predecible, luego es frecuente la sobreoferta y los precios bajos. Este escenario permite deducir que es urgente que los productores se asocien para ganar capacidad de negociación y ampliar su horizonte comercial hacia otras plazas. 


\section{La competitividad como desafío para los agronegocios}

La globalización de la economía, especialmente en el mercado agrario, busca el libre comercio de productos, para lo cual se promueve la reducción de aranceles y se definen barreras arancelarias que limitan la admisibilidad internacional; estos asuntos son de fácil solución para las grandes empresas, pero no para las pequeñas. En resumen, la globalización plantea una competencia entre grandes, tanto en el mercado interno como externo, en la que el mensaje es claro: "hay que ser competitivo o salir del mercado".

Pérez y Valietti (2008) entienden la competitividad como una capacidad para enfrentar mercados con posibilidad de lograr un buen resultado. Para el caso de los mercados agrarios, dominados por centrales de abastos y redes de mayoristas con alto poder competitivo, este es un escenario inconveniente para los productores agrarios Mipymes porque es un proceso inequitativo, injusto e inseguro, como lo sustenta Caicedo (2013). No es responsable dejar que el mercado se autorregule, sabiendo que esto no ha ocurrido por décadas y dejar a los campesinos a una suerte previsible, que solo les asegura pobreza, dejar su actividad, emigrar y que no haya relevo generacional. Este es el resultado de enfrentar a un grupo altamente competitivo con uno que no lo es.

Acevedo (2020) analiza una pregunta sin resolver, ¿cómo lograr que cada productor o sus pequeñas organizaciones logren ser competitivos? Esta es una interrogante difícil de resolver porque el proceso implica ganar productividad, crear ventajas competitivas, tener economía de escala y bajos costos, junto con otros elementos relacionados con la sostenibilidad social y cultural; además de otros factores externos sobre los que un pequeño o mediano productor no tiene control ni influencia (Rojas y Sepúlveda, 1999).

Ahora bien, la productividad depende de la calidad de la tierra y del acceso al agua, del potencial genético de los materiales con que se trabaja, de los sistemas de producción (que en la mayoría de los casos son empíricos y basados en saberes ancestrales, en la experiencia y en la poca capacidad técnica), entre otros. La ausencia de estos recursos, con frecuencia, hace que la productividad no sea sobresaliente.

Los factores externos están relacionados con el Gobierno y con el sector de negocios. El Gobierno es responsable de proveer bienes públicos o equipamiento necesario para la logística y el desarrollo rural, que determina las posibilidades de una vida digna para los habitantes del campo, tema en el cual se evidencia un gran atraso. El sector productivo, que está representado por los gremios, es quien da visibilidad y posicionamiento de los productos en los mercados (la mayoría de los productores Mipyme cuentan con poca representación). 
En ese orden de ideas, para que los productores agrarios puedan ganar visibilidad, respeto e incidencia ante el Gobierno y los mercados (ser competitivos) tienen que conformar grandes ASAL (Acevedo, 2020; Ferrando, 2015). Estas empresas surgen de pequeños aportes de los asociados, canalizando también el apoyo del Estado y las entidades de cooperación, con lo cual reinvierten excedentes y llegan a consolidar estructuras empresariales capaces de apoyar el agronegocio de cada asociado. De esta forma, los ASAL logran tener la capacidad de negociación necesaria para ser sostenibles y competitivas.

Conformar ASAL es conveniente para ganar competitividad, tanto en el ámbito de las Mipymes agrarias, como de las haciendas y empresas agroindustriales, dada la magnitud de los competidores que hay que enfrentar (Acevedo y Sánchez, 2020). En consecuencia, es necesario lograr altos niveles de integración, generar sinergias y una mayor capacidad de negociación y respuesta.

\section{Formas asociativas en economía social y solidaria (ESS)}

El sector de la economía solidaria se compone de una amplia gama de formas asociativas sin ánimo de lucro, cuyo concepto es conveniente precisar. El "SAL", para entidades de la economía solidaria como las cooperativas, hace referencia a que el asociado es propietario de sus aportes sociales y la revalorización acumulada, que puede recibir cuando se retire y que es una pequeña parte del valor de la empresa; pero no lo es del valor acumulado de la misma, fruto de la reinversión y de aportes recibidos de diversas instituciones, que es propiedad del sistema solidario de la región. El no tener la posibilidad de repartirse el valor de la empresa, pero sí de beneficiarse del servicio y apoyo de una gran organización, motiva al productor a permanecer como asociado y a defender el ASAL.

Nannetti y Duarte (2011) proponen clasificar las organizaciones de la Economía Social y Solidaria (ESS) en dos grupos, a saber:

Primer grupo: entidades que centran su acción en el beneficio social y no económico, como acciones comunales, fundaciones, corporaciones, asociaciones de productores (de tipo gremial), sindicatos, clubes deportivos, algunas cooperativas, gremios, entre otros, son promovidas y vigiladas por alcaldías y gobernaciones.

Segundo grupo: entidades que, como empresa asociativa, prestan servicios permanentes a sus asociados, como: "cooperativas, precooperativas, fondos de empleados, asociaciones mutuales, microempresas asociativas de trabajo, empresas comunitarias agrarias, asociaciones de productores, empresas agrarias de 
transformación-SAT, entre otras. Este grupo es reconocido como de economía solidaria (Conpes, 2010, p 10).

Chaves, Monzón, Pérez y Radrigán (2012) realizaron una investigación para Europa, Norte de África e Iberoamérica, con el fin de identificar el reconocimiento y posicionamiento de los términos como se identifica la ES en la administración pública, en el mundo académico y científico y en el sector de la economía social de cada país. Una de las conclusiones de este trabajo fue que, en la mayoría de los países, existe una alta reputación de la cooperativa para englobar el concepto de empresa asociativa y de ONG para entidades no lucrativas.

\section{Formas asociativas frecuentes en agronegocios solidarios en Colombia}

En Colombia casi todas las formas asociativas SAL son utilizadas para hacer negocios, aunque hayan sido diseñadas para otros fines, lo que justifica muchos fracasos. Sin embargo, esto también despierta el interés por investigar cuáles son las formas más convenientes para crear ASAL en diferentes escenarios, las más frecuentes son las asociaciones agropecuarias o campesinas, las cooperativas, las empresas comunitarias ${ }^{1}$, las sociedades agrarias de transformación (SAT), las sociedades de hecho² y la empresa asociativa de trabajo (EAT) ${ }^{3}$.

\section{Metodología}

El componente cuantitativo se generó a partir de la aplicación de encuestas a los líderes de los ASAL que componen la muestra. Fue necesaria la construcción del universo, dado que no existía una base de datos seleccionada y actualizada en tal sentido, lo que implicó la identificación de los ASAL existentes en cada uno de los 125 pueblos de Antioquia. En esta selección no se tuvo en cuenta aquellos con mínima actividad asociativa y operativa, por ejemplo: algunos trapiches comunitarios, vistos por los asociados solo como un medio para trasformar su caña, en el que cada cual procesa y vende por su lado; las asociaciones de productores de leche, formadas en

1 Creadas en el marco de la Reforma Agraria por la Ley 135 de 1961. Actualmente no es posible crear una empresa de este tipo.

2 Se constituyen por un contrato consensual entre dos o más socios, sin solemnidad alguna. Es una forma asociativa a la ligera, frecuente en grupos de campesinos, que operan informalmente y no se registran en ninguna entidad.

3 Los asociados aportan su capacidad laboral y algunos, además, entregan al servicio de la organización una tecnología, destreza, u otros activos necesarios para el cumplimiento de los objetivos de la empresa. 
función de un tanque de enfriamiento, por medio del cual se entrega el producto, y algunas granjas comunitarias que escasamente permiten un nivel de supervivencia. El universo encontrado suma 238 agronegocios.

Para el cálculo de la muestra se partió de un nivel de confianza del $95 \%$, una probabilidad de ocurrencia del $88 \%$ y un error muestral del $8 \%$, que es un poco alto, por considerar el elevado nivel de homogeneidad percibido en el comportamiento de la población estudiada, lo que hace referencia a una forma muy similar de manejar las organizaciones asociativas en la región. El resultado, al aplicar la fórmula estadística, fue de 50 ASAL, que constituyen una muestra representativa, los cuales fueron elegidos en forma aleatoria, ubicados en 29 pueblos en donde se logró entrevistar a líderes de las siguientes formas asociativas: 31 líderes de asociaciones de productores, 13 de cooperativas, 1 de SAT, 3 de corporaciones, 1 de SAS, 1 de acciones comunales y 1 de empresa agrícola comunitaria. Las encuestas se aplicaron presencialmente al líder de más alto rango que se pudo contactar, posterior a la firma de un consentimiento informado exigido por el Comité de Ética.

Los pueblos visitados fueron: San Vicente Ferrer, Granada, Marinilla, Santuario, San Luis, El Peñol, Rionegro, El Retiro, La Unión, La Ceja, Alejandría, Cocorná, Betania, Salgar, Urrao, Jericó, Ciudad Bolívar, Jardín, Támesis, Medellín, Yarumal, Campamento, Entrerríos, Don Matías, San Roque, Amalfi, Guadalupe, Sopetrán y Santa Bárbara.

El componente cualitativo se basó en entrevistas de profundidad a líderes de alta relevancia en el sector de los ASAL, diálogo con líderes de diversas formas asociativas de todas las subregiones de Antioquia, participación en eventos de estas organizaciones, observación de procesos y empresas. Las entrevistas de profundidad fueron grabadas, previo consentimiento, y para su desarrollo se contó con una guía temática no estructurada que fomentó un diálogo amplio. El componente cualitativo se consideró esencial en la construcción de una visión de contexto y para facilitar la interpretación global de los resultados cuantitativos. Como una forma de lograr mayor nivel de rigor en el análisis y facilitar la interpretación en contexto, se utilizó el software Atlas.ti para el procesamiento y análisis de las entrevistas de profundidad.

\section{Resultados de la investigación}

A continuación se exponen los principales resultados del funcionamiento de los ASAL más consolidados en el departamento de Antioquia. Estos datos se obtienen del análisis cualitativo y cuantitativo; se organizaron para facilitar el análisis comparativo entre formas asociativas, con lo cual se puede visualizar sus ventajas y desventajas, en procura de identificar cuáles pueden ser más convenientes. 
Tabla 1. Resultados de las entrevistas, encuestas y procesos de observación participativa

\begin{tabular}{|c|c|c|}
\hline Factor & Dato & Comentario \\
\hline Número de asociados & $88 \%$ fue menor a 200 & Mayoría ASAL tipo Mypime \\
\hline Vigilancia y control & $\begin{array}{l}76 \% \text { de los entrevistados sienten } \\
\text { que nadie los vigila }\end{array}$ & $\begin{array}{l}\text { No hay acompañamiento ni asesoría. } \\
\text { Los visitan cuando hay problemas }\end{array}$ \\
\hline Forma asociativa & $\begin{array}{l}62 \% \text { son asociaciones de producto- } \\
\text { res y } 26 \% \text { cooperativas }\end{array}$ & $\begin{array}{l}\text { Las cooperativas tienen mayor capaci- } \\
\text { dad empresarial }\end{array}$ \\
\hline \multirow{5}{*}{ Capacidades y actividades } & $\begin{array}{l}92 \% \text { con actividad comercial y ofre- } \\
\text { cen garantía de compra }\end{array}$ & $\begin{array}{l}\text { Todos apuntan a lo comercial como } \\
\text { objetivo central }\end{array}$ \\
\hline & $6 \%$ son integración vertical & Solo los grandes ASAL \\
\hline & $\begin{array}{l}68 \% \text { con procesos básicos de } \\
\text { agregación de valor, de los cuales } \\
\text { un } 35 \% \text { hace procesos de transfor- } \\
\text { mación }\end{array}$ & $\begin{array}{l}\text { Los más avanzados son las agroindus- } \\
\text { trias lechera y cafetera }\end{array}$ \\
\hline & $32 \%$ con sedes propias & Resto en comodato o alquiler \\
\hline & El $80 \%$ con alianzas productivas & $\begin{array}{l}\text { Priman los aliados mayoristas, agroin- } \\
\text { dustrias e instituciones }\end{array}$ \\
\hline $\begin{array}{l}\text { Voluntad del asociado para } \\
\text { colaborar }\end{array}$ & $\begin{array}{l}72 \% \text { reportan poca voluntad del } \\
\text { asociado }\end{array}$ & $\begin{array}{l}\text { Líderes cansados por sobrecarga de } \\
\text { trabajo }\end{array}$ \\
\hline Infidelidad del asociado & $72 \%$ entre inconformes e infieles & $\begin{array}{l}\text { Se gana fidelidad con formación } \\
\text { solidaria y logro de objetivos; en caso } \\
\text { contrario, prima el interés económico } \\
\text { individual }\end{array}$ \\
\hline Falta de liderazgo & Evidente en el $68 \%$ de los ASAL & $\begin{array}{l}\text { Dificultad para conformar cuadros } \\
\text { directivos }\end{array}$ \\
\hline $\begin{array}{l}\text { Resultados relevantes por ser } \\
\text { empresa asociativa }\end{array}$ & $\begin{array}{l}78 \% \text { han canalizado apoyos del } \\
\text { Gobierno y el } 54 \% \text { de las entidades } \\
\text { de cooperación }\end{array}$ & $\begin{array}{l}\text { Ante la debilidad financiera, es indis- } \\
\text { pensable el apoyo externo }\end{array}$ \\
\hline Resultados sociales & $\begin{array}{l}\text { El } 58 \% \text { de los ASAL decrece en su } \\
\text { número de asociados }\end{array}$ & $\begin{array}{l}\text { Deserción de insatisfechos y depura- } \\
\text { ción }\end{array}$ \\
\hline \multirow{7}{*}{$\begin{array}{l}\text { Aspectos comerciales y } \\
\text { financieros }\end{array}$} & $\begin{array}{l}\text { El } 64 \% \text { logra ventas menores a } 50 \\
\text { millones al mes }\end{array}$ & $\begin{array}{l}\text { Sistema financiero débil y de poco } \\
\text { impacto }\end{array}$ \\
\hline & $\begin{array}{l}\text { El } 58 \% \text { manifiesta lograr sostenibili- } \\
\text { dad financiera }\end{array}$ & $\begin{array}{l}\text { El resto dependen de apoyos externos } \\
\text { y están en nivel de supervivencia }\end{array}$ \\
\hline & $\begin{array}{l}\text { El } 52 \% \text { logra ventas estables y a } \\
\text { precios justos }\end{array}$ & Predominan las alianzas estratégicas \\
\hline & $\begin{array}{l}\text { El } 36 \% \text { de los ASAL paga al productor } \\
\text { al precio que venden }\end{array}$ & $\begin{array}{l}\text { Estas asociaciones no capitalizan, no } \\
\text { progresan y carecen de sostenibilidad } \\
\text { social y financiera }\end{array}$ \\
\hline & $\begin{array}{l}\text { El } 44 \% \text { de los ASAL vende al mejor } \\
\text { precio posible, sacan un margen para } \\
\text { su funcionamiento y crecimiento }\end{array}$ & $\begin{array}{l}\text { Son entidades fuertes, prósperas y que } \\
\text { prestan buenos servicios al asociado }\end{array}$ \\
\hline & $\begin{array}{l}\text { El } 54 \% \text { de los ASAL depende del } \\
\text { canal mayorista }\end{array}$ & Baja capacidad de negociación \\
\hline & $\begin{array}{l}16 \% \text { ha vendido al Gobierno, even- } \\
\text { tualmente. } 22 \% \text { está exportando }\end{array}$ & Oferta insuficiente y no sostenible \\
\hline
\end{tabular}




\begin{tabular}{|c|c|c|}
\hline Factor & Dato & Comentario \\
\hline \multirow{8}{*}{$\begin{array}{l}\text { Expectativa frente al futuro } \\
\text { del negocio }\end{array}$} & $\begin{array}{l}\text { El } 68 \% \text { de los dirigentes cree que su } \\
\text { ASAL va a crecer en los próximos años }\end{array}$ & $\begin{array}{l}\text { Actitud positiva con base en el apoyo } \\
\text { que reciben y en los buenos negocios }\end{array}$ \\
\hline & $\begin{array}{l}\text { Disminuir costos de producción a } \\
\text { valores internacionales para que el } \\
\text { ASAL pueda ser competitivo en un } \\
\text { escenario de globalización }\end{array}$ & $\begin{array}{l}\text { El desafío de bajar costos es perentorio } \\
\text { y permanente }\end{array}$ \\
\hline & $\begin{array}{l}\text { Necesidad de consolidarse como } \\
\text { integraciones verticales y horizon- } \\
\text { tales, siendo esta una estrategia de } \\
\text { competitividad }\end{array}$ & $\begin{array}{l}\text { Aplica para negocios de todos los } \\
\text { tamaños }\end{array}$ \\
\hline & $\begin{array}{l}\text { Ganar economía de escala vía creci- } \\
\text { miento, pero también mediante la } \\
\text { conformación de redes regionales y } \\
\text { alianzas estratégicas }\end{array}$ & $\begin{array}{l}\text { Necesario para ganar la posición com- } \\
\text { petitiva y capacidad de respuesta que } \\
\text { requiere un enfrentamiento comercial } \\
\text { entre grandes }\end{array}$ \\
\hline & $\begin{array}{l}\text { Implementar tecnologías y sistemas } \\
\text { productivos más apropiados para las } \\
\text { condiciones del mercado }\end{array}$ & Se refiere al enfoque territorial \\
\hline & $\begin{array}{l}\text { Monitorear las tendencias de los } \\
\text { mercados en cuanto al consumo }\end{array}$ & $\begin{array}{l}\text { Base para responder con rapidez a los } \\
\text { cambios en la demanda }\end{array}$ \\
\hline & $\begin{array}{l}\text { Cumplir los requerimientos normati- } \\
\text { vos a nivel nacional e internacional }\end{array}$ & $\begin{array}{l}\text { Es necesario para acceder a los mejo- } \\
\text { res mercados }\end{array}$ \\
\hline & $\begin{array}{l}\text { Acción permanente para lograr soste- } \\
\text { nibilidad y mejoramiento ambiental } \\
\text { en las áreas de influencia }\end{array}$ & $\begin{array}{l}\text { Requerimiento de las comunidades en } \\
\text { todos los niveles }\end{array}$ \\
\hline El modelo de negocio & $\begin{array}{l}\text { Los más relevantes son las integra- } \\
\text { ciones verticales y horizontales y los } \\
\text { basados en alianzas estratégicas }\end{array}$ & $\begin{array}{l}\text { Las Mipymes solo intentan vender de la } \\
\text { forma más básica }\end{array}$ \\
\hline \multirow{4}{*}{ Factores de éxito internos } & $\begin{array}{l}\text { Éxito administrativo y comercial } \\
\text { basado en el logro de resultados que } \\
\text { den solución real a los problemas y } \\
\text { necesidades de los asociados }\end{array}$ & $\begin{array}{l}\text { Válido para un } 38 \% \text { que tiene procesos } \\
\text { a cargo de expertos conscientes de } \\
\text { que los ASAL tienen que ser eficientes, } \\
\text { eficaces y competitivos }\end{array}$ \\
\hline & $\begin{array}{l}\text { Persistencia y fortaleza de unos } \\
\text { pocos líderes }\end{array}$ & $\begin{array}{l}\text { Asumen su papel como un apostolado } \\
\text { en favor de la comunidad }\end{array}$ \\
\hline & $\begin{array}{l}\text { Operar como integración vertical y } \\
\text { horizontal }\end{array}$ & $\begin{array}{l}\text { Ganando economía de escala, mayor } \\
\text { control del negocio y capacidad de } \\
\text { respuesta en los mercados }\end{array}$ \\
\hline & $\begin{array}{l}\text { La calidad en mejoramiento perma- } \\
\text { nente }\end{array}$ & $\begin{array}{l}\text { A través de la investigación, desarrollo } \\
\text { e innovación, y mediante el uso de } \\
\text { tecnologías de punta }\end{array}$ \\
\hline \multirow{3}{*}{ Factores de éxito externos } & $\begin{array}{l}\text { Apoyo por parte del Gobierno y } \\
\text { diferentes ONG }\end{array}$ & $\begin{array}{l}\text { Un pequeño ASAL, sin apoyo institucio- } \\
\text { nal, tiene poca probabilidad de éxito }\end{array}$ \\
\hline & $\begin{array}{l}\text { Las alianzas estratégicas con clientes } \\
\text { y entes de cooperación }\end{array}$ & $\begin{array}{l}\text { Permite producir y asegurar la venta, } \\
\text { tal y como lo propone el Gobierno }\end{array}$ \\
\hline & $\begin{array}{l}\text { La confianza que el ASAL inspira en } \\
\text { los mercados }\end{array}$ & $\begin{array}{l}\text { Implica preferencia por sus productos, } \\
\text { ser buscado para hacer negocios o } \\
\text { alianzas productivas y canalizar apoyo } \\
\text { del Gobierno, entre otros }\end{array}$ \\
\hline \multirow[b]{2}{*}{ Factores negativos internos } & $\begin{array}{l}\text { Deficiente educación y baja cultura } \\
\text { solidaria }\end{array}$ & Poco trabajo por parte de los dirigentes \\
\hline & $\begin{array}{l}\text { Bajo nivel de compromiso y } \\
\text { deserción por incompatibilidad de } \\
\text { intereses }\end{array}$ & $\begin{array}{l}\text { Comunidad profundamente competi- } \\
\text { tiva, y con muchas prevenciones para } \\
\text { emprender procesos solidarios }\end{array}$ \\
\hline
\end{tabular}


(viene)

\begin{tabular}{|c|c|c|}
\hline Factor & Dato & Comentario \\
\hline \multirow{6}{*}{ Factores negativos externos } & $\begin{array}{l}\text { Falta de apoyo del Gobierno y exceso } \\
\text { de obstáculos normativos }\end{array}$ & $\begin{array}{l}\text { El Gobierno desconoce la capacidad } \\
\text { real de cumplir por parte de los campe- } \\
\text { sinos }\end{array}$ \\
\hline & $\begin{array}{l}\text { Pocos trabajadores y con edades } \\
\text { avanzadas }\end{array}$ & Migración de jóvenes \\
\hline & $\begin{array}{l}\text { Los mayoristas ejercen presión en los } \\
\text { mercados para mantener los precios } \\
\text { bajos }\end{array}$ & $\begin{array}{l}\text { Sistema injusto e inequitativo montado } \\
\text { por el Gobierno }\end{array}$ \\
\hline & $\begin{array}{l}\text { Amenaza por inestabilidad y volatili- } \\
\text { dad de los precios }\end{array}$ & $\begin{array}{l}\text { Tanto por el efecto de las bolsas mer- } \\
\text { cantiles, como por plazas mayoristas }\end{array}$ \\
\hline & $\begin{array}{l}\text { Falta de lealtad y colaboración entre } \\
\text { ASAL }\end{array}$ & $\begin{array}{l}\text { Compiten entre sí con tanta fuerza } \\
\text { como los actores con ánimo de lucro }\end{array}$ \\
\hline & $\begin{array}{l}\text { Competir con empresas que actúan } \\
\text { con ilegalidad e informalidad }\end{array}$ & Esto les permite tener una mejor oferta \\
\hline \multirow{4}{*}{$\begin{array}{l}\text { ¿Qué otra forma asociativa } \\
\text { podría funcionar para su } \\
\text { modelo de negocio? }\end{array}$} & $\begin{array}{l}\text { El } 44 \% \text { dice que no tiene conoci- } \\
\text { miento acerca de otros modelos }\end{array}$ & $\begin{array}{l}\text { Se sienten cómodos con la que tienen } \\
\text { y acomodan los estatutos a sus nece- } \\
\text { sidades }\end{array}$ \\
\hline & $\begin{array}{l}\text { El } 56 \% \text { ha considerado la posibilidad } \\
\text { de cambiar su forma asociativa }\end{array}$ & $\begin{array}{l}\text { Desean transformarse en empresa } \\
\text { sólida }\end{array}$ \\
\hline & \multirow{2}{*}{$\begin{array}{l}68 \text { \% cambiaría hacia la cooperativa } \\
\text { y el } 32 \% \text { preferiría pasar a una forma } \\
\text { con ánimo de lucro }\end{array}$} & $\begin{array}{l}\text { Creen que la cooperativa es la mejor } \\
\text { forma para hacer empresa. }\end{array}$ \\
\hline & & $\begin{array}{l}\text { Otros buscan eludir el pago de impues- } \\
\text { tos y rendición de cuentas }\end{array}$ \\
\hline \multirow{8}{*}{$\begin{array}{l}\text { Impactos socioeconómicos } \\
\text { generados por su empresa }\end{array}$} & $\begin{array}{l}\text { El } 88 \text { \% se siente satisfecho y desea } \\
\text { mejorar sus ingresos, además de } \\
\text { alcanzar la sostenibilidad de su } \\
\text { negocio }\end{array}$ & $\begin{array}{l}\text { Lo más valorado es la mejora en ingre- } \\
\text { sos y los servicios recibidos, sin que } \\
\text { esto signifique que el único interés sea } \\
\text { ganar dinero }\end{array}$ \\
\hline & $\begin{array}{l}\text { El } 70 \% \text { desea mejoras en su calidad } \\
\text { de vida, en aspectos relacionados } \\
\text { con la educación, salud, cultura, } \\
\text { entre otros }\end{array}$ & $\begin{array}{l}\text { El principal logro es la calidad de vida } \\
\text { de la familia del asociado }\end{array}$ \\
\hline & $\begin{array}{l}\text { El } 78 \% \text { considera importante } \\
\text { incrementar la producción local en } \\
\text { la zona }\end{array}$ & $\begin{array}{l}\text { Un buen ASAL motiva a invertir, puesto } \\
\text { que promueve el respaldo y apalanca } \\
\text { el progreso }\end{array}$ \\
\hline & $\begin{array}{l}\text { El } 90 \% \text { manifiesta sentir un am- } \\
\text { biente favorable de colaboración y } \\
\text { convivencia }\end{array}$ & $\begin{array}{l}\text { Operan como una gran familia. Este es } \\
\text { uno de los principales motivos por los } \\
\text { cuales los campesinos quieren perma- } \\
\text { necer en los ASAL }\end{array}$ \\
\hline & $\begin{array}{l}\text { El } 54 \text { \% valora las acciones de solida- } \\
\text { ridad hacia personas con dificultades }\end{array}$ & $\begin{array}{l}\text { Los fondos de solidaridad o las campa- } \\
\text { ñas entre asociados han beneficiado a } \\
\text { las personas con dificultades }\end{array}$ \\
\hline & $\begin{array}{l}\text { El } 38 \% \text { alcanzó mejoras en bienes } \\
\text { públicos }\end{array}$ & $\begin{array}{l}\text { ASAL muy pequeños, y con poca repre- } \\
\text { sentatividad, tienen poca importancia } \\
\text { para los dirigentes políticos }\end{array}$ \\
\hline & $\begin{array}{l}\text { Generación de empleo decente, } \\
\text { tanto a nivel agroindustrial, como en } \\
\text { unidades productivas }\end{array}$ & $\begin{array}{l}\text { Generar bienestar es un objetivo cen- } \\
\text { tral de un ASAL }\end{array}$ \\
\hline & $\begin{array}{l}\text { Hacer más interesantes los procesos } \\
\text { y la vida para los campesinos y sus } \\
\text { grupos familiares, de modo que per- } \\
\text { manezcan en su territorio y quieran } \\
\text { seguir siendo productores }\end{array}$ & $\begin{array}{l}\text { Aun así, solo el } 32 \text { \% cree que está } \\
\text { logrando retener a los jóvenes, ya que } \\
\text { los micro ASAL no ofrecen un futuro } \\
\text { económico positivo }\end{array}$ \\
\hline
\end{tabular}




\begin{tabular}{|c|c|c|}
\hline Factor & Dato & Comentario \\
\hline \multirow{5}{*}{$\begin{array}{l}\text { Falencias de los ASAL tipo } \\
\text { Mipyme }\end{array}$} & Deficiente administración & $\begin{array}{l}\text { Se debe a la poca capacitación de los } \\
\text { líderes, a su escasa visión empresarial y } \\
\text { a la imposibilidad financiera de delegar } \\
\text { la dirección en expertos }\end{array}$ \\
\hline & $\begin{array}{l}\text { Distintos ASAL no cuentan con una } \\
\text { estructura empresarial, están bajo el } \\
\text { control de un líder que hace diversas } \\
\text { funciones y que, con frecuencia, no } \\
\text { sabe si gana o pierde }\end{array}$ & $\begin{array}{l}\text { Es la forma asociativa más común, con } \\
\text { frecuencia terminan en problemas } \\
\text { y hasta el patrimonio del líder corre } \\
\text { riesgo }\end{array}$ \\
\hline & $\begin{array}{l}\text { Muchos ASAL surgen como producto } \\
\text { de un proyecto, duran mientras se } \\
\text { ejecuta y luego desaparecen }\end{array}$ & $\begin{array}{l}\text { Algunos permanecen en una pobre } \\
\text { posición competitiva, a la espera de } \\
\text { nuevos proyectos }\end{array}$ \\
\hline & $\begin{array}{l}\text { No logran acceso a mercados en los } \\
\text { que se paga un mejor precio por los } \\
\text { productos }\end{array}$ & $\begin{array}{l}\text { Tienen poca capacidad de respuesta, } \\
\text { oferta pequeña e inestable, calidad } \\
\text { heterogénea, debilidad logística, entre } \\
\text { otras }\end{array}$ \\
\hline & $\begin{array}{l}\text { No logran satisfacer el objeto para el } \\
\text { cual fueron creados }\end{array}$ & $\begin{array}{l}\text { Generan insatisfacción en los asocia- } \\
\text { dos, poca gobernabilidad y deserción }\end{array}$ \\
\hline \multirow{3}{*}{$\begin{array}{l}\text { Beneficios derivados de ser } \\
\text { una entidad pequeña }\end{array}$} & $\begin{array}{l}\text { Informalidad en el manejo de los } \\
\text { procesos }\end{array}$ & $\begin{array}{l}\text { Permite agilizar las decisiones y la } \\
\text { prestación de servicios, además de } \\
\text { bajar los costos }\end{array}$ \\
\hline & $\begin{array}{l}\text { Menos presión por cumplir normas y } \\
\text { poco seguimiento por parte de entes } \\
\text { de control }\end{array}$ & No les conviene ser muy visibles \\
\hline & $\begin{array}{l}\text { Acomodan los estatutos a sus necesi- } \\
\text { dades particulares }\end{array}$ & $\begin{array}{l}\text { Como son grupos pequeños y homo- } \\
\text { géneos, les es más fácil tomar algunas } \\
\text { decisiones }\end{array}$ \\
\hline
\end{tabular}

Fuente: elaboración propia

\section{Análisis de los resultados}

El panorama general de los ASAL en Antioquia, con base en la experiencia de los autores y el diálogo con múltiples actores, se compone de unas pocas empresas consolidadas y centenares de pequeñas organizaciones, la mayoría con alto grado de informalidad, sin capacidad para generar un impacto significativo en el desarrollo agrario de su territorio. Hay acuerdo en que la mayoría de estas organizaciones no fueron creadas para hacer negocios ni tienen una estructura empresarial para esto.

El sentir general de los campesinos es que la comercialización de sus productos es el problema más relevante y un factor permanente de incertidumbre; entienden que juntos les puede ir mejor, que primero hay que vender y luego producir, que hay que hacer alianzas productivas; sin embargo, no encuentran la manera de organizar las ideas y emprender un proceso viable y sostenible, en parte por la escasez de líderes y su poca visión global, por lo que temen comprometerse con acciones de gran alcance. 
Muchos campesinos afirman que se sienten cada día más pobres, comprenden que este es su problema y que muy pocos se interesan por ellos, por lo que no encuentran otra salida que emigrar a buscar suerte en otro lugar. Señalan que el Gobierno solamente les propone crear pequeñas asociaciones, como canal para llevar algunos apoyos o proyectos, pero nunca se ha promovido una forma asociativa de gran alcance; además, aunque pueden llevar muchos años participando en procesos asociativos, dicen no saber nada acerca de formas asociativas para hacer negocios, aunque les interesaría desarrollarlas.

Se percibe un mal ambiente para procesos asociativos, porque abunda el egoísmo entre quienes tienen los medios económicos y la prevención y el miedo en los que no cuentan con la capacidad económica, ya que siempre salen perdiendo con cada propuesta que se les presenta. Algunos líderes asociativos dicen que para desarrollar empresas asociativas grandes con campesinos, hay que hacer un gran trabajo de sensibilización, dado que el campesino posee una baja autoestima, es difícil de animar o empoderar.

La cultura de emprendimiento en los campesinos enfrenta varios desafíos. Por un lado, el miedo a emprender con independencia del Estado pensando que ello les resta beneficios. Por otro lado, se enfrentan al desconocimiento en el sostenimiento de un emprendimiento a gran escala o que tenga influencia en todos los estabones de la cadena de producción y comercialización. Estos desafíos son puntos de análisis para lograr el empoderamiento de los actores del sector rural en función de la productividad local con retribución justa.

Una percepción, bastante común, es que la comunidad en general padece de un egoísmo colectivo que parece genético y que aflora ante la oportunidad. Si se ve la opción de sacar ventaja, así sea insignificante y no sostenible, algunos la aprovecharán violando sus compromisos con la organización. Otro aspecto de gran impacto es la alta migración de jóvenes, que hace que en los campos están quedando los adultos, la mayoría de ellos de edad avanzada, lo que pone en riesgo la sostenibilidad de la actividad agraria, si se proyecta a unos pocos años. Es urgente desarrollar estrategias que muestren a los jóvenes la actividad agropecuaria como un proceso interesante, con tecnología apropiada que facilite la labor, con agroindustria, con procesos de mercadeo, que genere ganancias, entre otros.

Con relación a las formas asociativas, es frecuente escuchar a dirigentes de asociaciones decir que añoran la forma cooperativa porque les permitía recibir al retiro sus aportes acumulados y con revalorización, además de respaldo y beneficios por diferentes vías, lo que les facilitaría consolidar su negocio; sin embargo, el modelo asociativo se percibe como algo complejo, difícil de consolidar y dirigir, con mucha 
formalización y cargas tributarias y por eso dicen que es el modelo a implementar para grandes negocios y otras formas más sencillas e informales para los pequeños negocios.

Se observó que la mayoría de ASAL realizan grandes procesos de depuración de asociados, en parte porque cuando las organizaciones surgen de afán, entra mucha gente, pero cada uno tiene una mezcla de intereses diferentes y cuando ve que no logra los que más le importan, unos se retiran por su cuenta y otros se vuelven un caso problema.

\section{Discusión de los resultados}

El universo estudiado corresponde a los ASAL más relevantes y es una pequeña porción de los ASAL existentes en el departamento, la muestra elegida representa el $21 \%$ del universo, y de ella el 88 \% es Mipyme. Si se mira el total de los ASAL bajo todas las formas asociativas y tamaños, el resultado de Mipymes se estima que es cercano al $100 \%$, lo que respalda varias conclusiones en las que se habla de la pobre posición competitiva y de la necesidad de grandes emprendimientos, con enfoque en sostenibilidad y competitividad.

Este análisis lo respalda un reporte de la Confecoop (2011), válido solamente para cooperativas agrarias, que suelen ser las de mayor solidez, en el cual se dice que un $97 \%$ son entre pequeñas y microempresas (si se incluyen las medianas, se acerca al 100\%), y el 3 \% lo conforman una élite de cooperativas, la mayoría cafeteras y lecheras.

Es evidente el alto nivel de informalidad y fracaso en los emprendimientos asociativos, aunque no se encontró datos consolidados. Esto significa que se debe asumir un gran desafío en cuanto al diseño de nuevas propuestas a emprender y de las estrategias de acompañamiento para incrementar los proyectos exitosos. Pero este problema no es solo del sistema asociativo, sino de los procesos de emprendimiento en general. La Asociación de Cámaras de Comercio Colombianas (Confecámaras) publicó en El Espectador (2018) un análisis en el que señala que el 70 \% de las nuevas empresas colombianas fracasan en los primeros cinco años. En tanto que la Asociación de Cámaras de Comercio de Estados Unidos dice que el 80 \% fracasan en dos años y, de las que sobreviven, el $80 \%$ en cinco años, un $4 \%$ después de siete años. En su análisis del por qué fracasan, las Cámaras plantean como la principal causa el creer que si alguien es bueno en una actividad técnica, entonces será exitoso como empresario, sin considerar que le quedan faltando las habilidades gerenciales, en manejo de la información, en mercadeo y ventas, habilidades relacionales, la vocación de empresario, la capacidad de lucha, de persistencia, de resiliencia, entre otras. 
En esta investigación se recomienda crear en cada pueblo o subregión un ASAL con la capacidad de enfrentar competidores de talla mundial, lo cual es respaldado por Saúl Sanmiguel Ortiz (2018), en su calidad de Gerente de la Cooperativa de Caficultores del Huila, Cadefihuila; por Álvaro Ernesto Palacio Peláez, presidente de Asohofrucol y por el Gobierno español, quien ha evidenciado la urgente necesidad de las cooperativas por ganar competitividad.

Otro factor relevante que respalda esta iniciativa, y en cuyo proceso participaron los autores, es una política pública para apoyar el desarrollo de la economía solidaria en el Departamento de Antioquia, que es la Ordenanza 68 del 2017, cuyo componente 4 propone crear empresas SAL con enfoque en sostenibilidad y competitividad, con siete dependencias de alto nivel de la Gobernación del departamento comprometidas con el apoyo a todas las iniciativas.

Un resultado que vale la pena resaltar es que la forma asociativa más conveniente para desarrollar ASAL con pequeños y medianos productores es la cooperativa, lo cual concuerda con la exitosa experiencia de cafeteros, lecheros, algunos arroceros, plataneros, del sector hortofrutícola, entre otros. También es importante mencionar como para los españoles y los italianos es la forma asociativa predominante, lo que es reportado en la literatura y además se tuvo un amplio diálogo al respecto con algunos investigadores en eventos académicos.

Otro resultado interesante es el creciente interés de algunos líderes en conformar o transformar suS ASAL en organizaciones con ánimo de lucro. Al respecto hay bastante experiencia reportada en literatura española, especialmente cuando se trata de grupos pequeños, altamente homogéneos en su capacidad económica y en sus necesidades y aspiraciones, para quienes la forma que vale la pena considerar es la Sociedad Agraria de Transformación - SAT, como lo muestra la experiencia de Hass Colombia SAT, y que explica en detalle Vidal, Segura y Rayos (2001) en sus investigaciones en la Provincia de Alicante (España).

\section{Conclusiones}

La forma asociativa que predomina es la asociación de productores, la mayoría nacidas por orientación del Gobierno para ejecutar algún proyecto, convocados en tiempo récord, sin proceso previo de sensibilización, capacitación y acompañamiento, por lo que operan como un ejercicio transitorio que dura hasta donde aguante el líder, razón por la cual nacen y mueren todo el tiempo.

La mayoría de los líderes solo conocen la forma asociativa que dirigen, no saben por qué eligieron esa, no conocen la normatividad pertinente y creen que vía estatutos se arregla todo. 
El $88 \%$ de la muestra son considerados ASAL tipo mypime, con poca sostenibilidad social y financiera, y con mínima capacidad de generar impacto positivo en el desarrollo agropecuario.

Poco éxito en pequeños ASAL que intentan negociar con comerciantes detallistas de la capital, dado que no tienen capacidad de respuesta por el poco volumen, la oferta inestable, la calidad heterogénea, los altos costos de transporte, los altos riesgos en la distribución y a que la responsabilidad queda en manos del líder, porque no alcanza a tener empleados suficientes.

Los grandes compradores buscan ASAL sólidos con los que se puedan hacer alianzas comerciales, capaces de garantizar suministro todo el año, con calidad sostenida y certificada, con capacidad de respuesta, entre otras.

El objeto principal de la totalidad de los ASAL es la comercialización, actividad que un $92 \%$ realiza y el $8 \%$ restante aspira a iniciar ventas próximamente, pero solo la mitad dice que logran ventas estables y a precios justos, dado que sigue siendo el mayorista su principal canal de venta.

Se observa una débil cultura solidaria, lo que lleva a un deficiente relevo generacional, por lo que es alta la edad de los dirigentes que llevan décadas manejando organizaciones.

Los logros más relevantes que reportan la mayoría de los líderes son las alianzas estratégicas y la obtención de apoyos del Gobierno y de los entes de cooperación.

El éxito administrativo y comercial de los más grandes ASAL se ha logrado gracias a que estos procesos están a cargo de expertos, y a la persistencia y fortaleza de unos pocos líderes.

Hay un exceso de normatividad del Gobierno que exige mucho a las organizaciones campesinas, y que desconoce su poca capacidad real de cumplir tales normas.

La alta deserción de los asociados a los ASAL se debe a que muchos tienen objetivos diferentes a los fundamentales de la organización y no encuentran justificable su presencia en ellas y a otros los tienen que sacar, en su mayoría por egoístas, ventajosas, con poca cultura de pago, inconformes a ultranza, o con aspiraciones desmedidas.

Los pequeños ASAL se reparten todo lo que consiguen y no capitalizan, mientras que las organizaciones más maduras y prósperas venden al mejor precio posible, sacan un margen para su funcionamiento y crecimiento, y le pagan al productor sin cuota de sostenimiento.

En algunas asociaciones de productores ocurre que, como los asociados saben que en el momento del retiro no recibirán nada de lo que han aportado, nadie quiere pagar una cuota extra, y muchos tienen poco afán por cumplir con el pago de 
las cuotas de sostenimiento. La mayoría de los ASAL han considerado la posibilidad de cambiar su forma asociativa, porque ven la necesidad de consolidar su proyecto como empresa; así, la forma empresarial preferida para el 68 \% de ellos es la cooperativa; el otro 32\% prefiere cambiar por una forma con ánimo de lucro, pero con muy débiles argumentos de soporte.

La cooperativa es la forma asociativa más conveniente para desarrollar ASAL, dado que la legislación le permite consolidar una estructura empresarial capaz de ser competitiva, que le es prioritario prestar buenos servicios al asociado, promover la integración y convivencia, y mantener enfoque más en el buen vivir que en el dinero.

\section{Recomendaciones}

Es importante promover un proceso participativo que permita llegar a acuerdos respecto del modelo de negocio y a una forma empresarial SAL, capaz de ser competitiva y de impactar positivamente a una gran comunidad campesina, que integre varios ASAL pequeños y permita la entrada de todos los productores que lo deseen. Asimismo, es necesario promover la búsqueda y la formación de líderes en los ASAL, preferiblemente jóvenes, para asegurar su sostenibilidad y progreso.

Se recomienda crear una cooperativa en cada pueblo o subregión, que comercialice productos multilínea e insumos al menor precio posible y que maneje alianzas productivas, de tal modo, que al ser un proceso más global, grande y complejo, pueda delegar en expertos la administración (de acuerdo con lo planteado por Acevedo [2020]).

Para lograr resultados rápidos, consistentes y sostenibles en la creación de ASAL con alto potencial, es necesario un apoyo coordinado entre el Estado y las ONG que intervienen en el territorio, dada la escasa capacidad de inversión de los campesinos.

El modelo de negocio del ASAL recomendado para los pueblos debe promover el consumo local de lo que produce y llevar los excedentes a mercados de mayor demanda y mejor precio, vía conformación de redes empresariales de gran capacidad y alcance.

Las formas empresariales SAL pertinentes en tiempos de globalización tienen que ser competitivas y eficaces para poder pagar impuestos, cumplir normas, certificar sus procesos y lograr los objetivos por los que fueron creados. No pueden depender de apoyos esporádicos del Gobierno, ni de ningún otro origen. 


\section{Referencias}

Acevedo González, G. y Sánchez C. Y. (2020). Competitividad de los Agronegocios y papel de las entidades asociativas con y sin ánimo de lucro. En N. L. Murga Valderrama, P. A. Rituay Trujillo, J. A. Campos Trigoso y R. Meleán Romero (Ed.), Agronegocios y ganadería sostenible (pp. $97-$ 115). Universidad Toribio Rodríguez de Mendoza de Amazonas; Universidad del Zulia.

Acevedo González, G. y Palacio M. J. (2017). Evaluación de factores que afectan la comercialización de agro-productos de pequeños y medianos productores del Oriente Antioqueño. Colombia, Journal of Agriculture and Animal Sciences, 5(2), 60-69. 10.22507/jals.v5n2a5

Acevedo González, G. A. (2019). Cómo dinamizar la economía de un pueblo agrario. Revista de Investigaciones Unisarc, 1(1), 56-63. https://www.unisarc.edu.co/Archivos/Contenido/ Archivos/99iu4bbzpu-revista-2019-1.pdf

Bendini, M. y Steimbreger, N (2011). Ocupaciones y movilidades en pueblos rurales de la Patagonia. Una mirada desde lo agrario. Mundo Agrario, 12(23), http://www.mundoagrario.unlp.edu.ar/ article/view/v12n23a03/173

Cáceres Gómez, L. S., Pardo Enciso, C. E. y Torres, A. M. (2013). La asociatividad y las cadenas productivas: una alternativa de desarrollo para el municipio de Yopal, Casanare. Cooperativismo y Desarrollo, 21(102), 69-75.

Caicedo, D. J. F. (2013). La intermediación como un impedimento al desarrollo del pequeño productor de Medellín. Revista Corpoica Ciencia y Tecnología Agropecuaria, 14(1), 27-32. https:// www.redalyc.org/articulo.oa?id=449945181004

Cárdenas Mora, S. M. y Manzanares Mendoza, K.J. (2017). Las organizaciones de economía solidaria como mecanismo de integración de pequeños y medianos productores de yuca en Yopal Casanare. Cooperativismo y Desarrollo, 110(25), 27-36. DOI: https://doi.org/10.16925/ co.v25i110.1762.

Cervantes, R. (2008). La sociedad agraria de transformación en España: un análisis histórico. Cirec. Revista de Economía Pública Social y Cooperativa, (63), 65-87, https://www.redalyc.org/ pdf/174/17412307003.pdf

Chaves, R., Monzón, J., Pérez, J. y Radrigán, M. (2012). La economía social en clave internacional. Cuantificación, reconocimiento institucional y visibilidad social en Europa, Iberoamérica y Norte de África. Revista de Estudios Cooperativos, (112), 122-150. 


\section{Gabriel Antonio Acevedo González, Yomar Javier Sánchez Caicedo}

Confecoop. (2011). Las cooperativas de trabajo asociado en Colombia. http://www.confecoop. coop/observatorio/11/files/doc11.pdf

Consejo Nacional de Política Económica y Social (Conpes). 3639 (2010) Política de desarrollo empresarial para el sector de la economía solidaria. Consejo Nacional de Política Económica y Social, Departamento Nacional de Planeación.

Cornare, Alianza Clima y Desarrollo, Fundación Natura y WWF. (2015). Análisis socioeconómico del Oriente Antioqueño. Anexo 1. https://www.cornare.gov.co/Plan-crecimiento-verde/Anexo1. Analisis-Socioeconomico-Oriente-Antioqueno.pdf

Departamento Nacional de Estadística de Colombia (DANE). (2015). Tercer Censo Nacional Agropecuario de Colombia de 2014. https://www.dane.gov.co/index.php/estadisticas-por -tema/agropecuario/censo-nacional-agropecuario-2014

El Espectador. (2018). ¿Por qué el 70\% de las empresas en Colombia fracasan en los primeros cinco años? https://www.elespectador.com/economia/por-que-el-70-de-las-empresas-en-colombia-fracasan-en-los-primeros-cinco-anos-article-820897/

Ferrando Perea, A. (2015). Asociatividad para mejorar la competitividad de pequeños productores agrícolas. Anales Científicos, 6(1), 177-185. http://revistas.lamolina.edu.pe/index.php/ acu/article/view/779\#: :text=El\%20an\%C3\%A1lisis\%20de\%20los\%20resultados,la\%20 cooperativa\%20y\%20las\%20comunidades

Gobernación de Antioquia y Asamblea Departamental. (2017). Ordenanza 68 del 2017. "Por medio de la cual se crea la Política Pública para la Economía Solidaria y Decreto reglamentario". https://n9.cl/9e4ia

Nannetti R. G. y Duarte, Q. G. (2002). Bases constitucionales de las formas asociativas de la economía solidaria [Tesis para obtener el título de Abogado, Pontificia Universidad Javeriana]. https://studylib.es/doc/5256081/informsaci\%C3\%B3n---pontificia-universidad-javeriana

Pérez Bengochea, V.(2008). Competitividad empresarial, un nuevo concepto. http://www.degerencia.com/articulo/competitividad_empresarial_un_nuevo_concepto

Posada H. G.J. (2010). Agrupación de municipios colombianos según características de ruralidad. Tesis de grado, Universidad Nacional de Colombia sede Medellín. http://www.bdigital.unal. edu.co/3261/1/71672321.2010.pdf 
22 Formas asociativas sin ánimo de lucro más convenientes para desarrollar agronegocios en el Departamento de Antioquia

Programa de Naciones Unidas para el Desarrollo (PNUD). (2011). Colombia rural, razones para la esperanza. Informe Nacional de Desarrollo Humano.

Rojas, P. y Sepúlveda, S. (1999). El reto de la competitividad en la agricultura. IICA. http://repiica. iica.int/docs/B0245e/B0245e.pdf

Sanmiguel Ortiz, S. (2018). Cooperativismo ha sido mirado por encima del hombro: Cadefihuila. Diario La Economía. https://diariolaeconomia.com/tomemos-cafe/item/3566-cooperativismo-ha-sido-mirado-por-encima-del-hombro-cadefihuila.html

Vidal, F., Segura, B. y Rayos, J. A. (2001). Situación económico-financiera de las sociedades agrarias de transformación (SAT) de comercialización hortofrutícola de la provincia de Alicante. https:// pdfs.semanticscholar.org/4caa/a204e15b2eb67d1208373ed7aed6a7343c4e.pdf 